\title{
ARTIKELEN
}

\section{Recht op een bankrekening?}

Mr. dr. J. Sybesma*

\section{Inleiding}

In zijn uitspraak van 3 februari $2021^{1}$ oordeelde het Gerecht van Aruba (in kort geding) over het openen van bankrekeningen bij een commerciële bank en de vraag of je daar recht op hebt. In dit geval oordeelt de rechter daarover positief. Deze uitspraak roept enkele vragen op. Heeft iedereen recht op een bankrekening? Doorkruist de rechter met dit gebod niet de contractvrijheid van de commerciële bank? Zijn er uit de uitspraak en mogelijk andere uitspraken op dit terrein spelregels te halen? Met deze bijdrage tracht ik antwoord te geven op deze vragen. Daarbij realiseer ik me dat de materie complex is en vele (juridische) facetten kent. Ik ga derhalve niet uitputtend in op deze facetten doch formuleer een eerste antwoord op de vraag of er een recht op een bankrekening bestaat.

Mijn aanpak is als volgt. Ik ga eerst in op het karakter van een commerciële bank. Commerciële banken zijn rechtspersonen net als andere rechtspersonen ingevolge Boek 2 van het Burgerlijk Wetboek (BW). Zijn ze desalniettemin toch anders? Vervolgens sta ik stil bij de klanten van commerciële banken. De ene klant is immers de andere niet. Kan er onderscheid worden gemaakt in soorten klanten: particuliere klanten, zakelijke klanten, bestaande klanten en nieuwe klanten? Daarna sta ik stil bij de ontwikkelingen zoals die zich op dit gebied hebben voorgedaan op grond van jurisprudentie. Het was een recente uitspraak van de Arubaanse rechter die mij tot deze bijdrage bracht. Er zijn daarnaast nog vele uitspraken afkomstig uit de diverse delen van het Koninkrijk. Ik sta vooral stil bij uitspraken met betrekking tot het Caribische deel van het Koninkrijk. Ik sluit vervolgens af met een conclusie.

\section{Commerciële banken}

Een commerciële bank is primair een bedrijf, een naamloze vennootschap (NV), zoals geregeld in Boek 2 BW. Primair doel van een NV is winstmaximalisatie voor de aandeelhouders. Omdat banken geld krijgen van hun klanten en daarmee hun bedrijfsactiviteiten verrichten en ter bescherming van de monetaire stabiliteit, acht de wetgever het belangrijk om regels vast te stellen ter verzekering dat een bank voorzichtig omgaat met de haar toevertrouwde gelden.

* Mr. dr. J. Sybesma is redactielid van het Caribisch Juristenblad. Voor zijn pensionering werkte hij bij de Centrale Bank van Curaçao en Sint Maarten (CBCS). Hij is tevens lid van de Raad van Advies Curaçao en bijzondere rechter bij het Gemeenschappelijk Hof van Justitie van Aruba, Curaçao, Sint Maarten en Bonaire, Sint Eustatius en Saba.

1 GEA Aruba 3 februari 2021, ECLI:NL:OGEAA:2021:33. 
In de Landsverordening toezicht bank- en kredietinstellingen ${ }^{2}$ staan regels ten aanzien van prudentieel toezicht. Dit houdt in dat de Centrale Bank van Curaçao en Sint Maarten (CBCS), als financieel toezichthouder, erop toeziet dat banken aan hun financiële verplichtingen kunnen voldoen. Zaken als solvabiliteit en liquiditeit, het vermijden van te hoge concentraties van leningen en dergelijke zijn aan strenge regels gebonden. Daarnaast oefent de CBCS ook zogenoemd gedragstoezicht ${ }^{3}$ uit dat gericht is op onder meer de betrouwbaarheid, deskundigheid, transparantie en zorgplicht van de bank. Kortom, om een commerciële bank te zijn ben je onderworpen aan strikte kaders waarbinnen je mag opereren. In Aruba geldt vergelijkbare financiële toezichtwet- en regelgeving, hoewel er nog geen gedragstoezicht is.

Daarmee is de commerciële bank er nog niet. Het raamwerk waarbinnen een commerciële bank opereert is namelijk nog ingewikkelder. Immers, geldstromen van personen en bedrijven lopen via bankrekeningen. ${ }^{4}$ Banken vormen met elkaar een wereldwijd netwerk voor financiële transacties. Tegenwoordig vliegt via elektronisch bankieren het geld razendsnel de wereld rond. ${ }^{5}$ Het is dus via dit netwerk dat naast legitieme financiële transacties, ook geld verkregen uit duistere zaken wordt rondgestuurd. Geld wordt op deze manier witgewassen. ${ }^{6}$ Overheden willen witwassen bestrijden en komen met allerlei vereisten voor commerciële banken om er zorg voor te dragen dat deze illegale activiteiten worden tegengegaan. Ik heb een hele tijd geleden betoogd dat het eigenlijk raar is dat een overheidstaak wordt neergelegd bij onder andere commerciële banken. ${ }^{7}$ Hoe het ook zij, zo'n $2,7 \%$ van het wereldwijde bruto nationaal product wordt jaarlijks witgewassen. ${ }^{8}$

Sinds de terroristische aanslag op de Twin Towers op 11 september 2001 komt daar de bestrijding van de financiering van terroristische acties bij. Overheden worden aangestuurd door internationale organisaties als de (Caribbean) Financial Action Task Force ((C)FATF). ${ }^{9}$ Het gaat nog verder. De Verenigde Naties en de Europese Unie vaardigen regelmatig lijsten uit van naties, instellingen, organisaties en personen die volgens deze supranationale instanties geïsoleerd moeten worden onder andere vanwege mensenrechtenschendingen. En op grond van de Sanctielandsverordening van Curaçao leidt dat tot

2 PB 1994, 4 en geharmoniseerd met andere financiële toezichtwetgeving door PB 2015, 67.

3 www.centralbank.cw/legislation-guidelines/conduct-supervision/provisions; vgl. art. 1:25 Wet op het financieel toezicht $(\mathrm{Wft})$.

4 W. Boonstra, 'Op naar een girale wereld', RaboReseach 26 oktober 2017, https://economie.rabobank.com/ publicaties/2017/oktober/op-weg-naar-een-girale-wereld/; 'Vijf redenen waarom cashless betalen de toekomst is', Banken.nl 5 juni 2018, www.banken.nl/nieuws/20927/vijf-redenen-waarom-cashless-betalen-detoekomst-is.

5 'Total transaction value in the Digital Payments segment is projected to reach US\$ 6,685,102m in 2021', zie www.statista.com/outlook/dmo/fintech/digital-payments/worldwide.

6 The war against money-laundering is being lost, Economist April 17, 2021; www.economist.com/financeand-economics/2021/04/12/the-war-against-money-laundering-is-being-lost.

7 J. Sybesma, 'De terreur van de Lif en de Mot', AJV Nieuwsbrief 2010, afl. 1, p. 13-18.

8 'Witwassen: de donkere kant van het wereldwijde financiële systeem', Amigoe 5 maart 2021; https:// caricom.org/launch-of-the-report-of-the-high-level-panel-on-international-financial-accountabilitytransparency-and-integrity-for-achieving-the-2030-agenda.

9 Ook dit is interessant maar buiten het kader van deze bijdrage; waar halen dit soort organisaties hun bevoegdheden vandaan om soevereine staten hun wil op te leggen? Ze zijn immers geen volkenrechtelijke organisaties in de zin van art. $2 \mathrm{~b}$ Staatsregeling van Curaçao. 
maatregelen die ook betrekking hebben op het betalingsverkeer dat door commerciële banken in acht moet worden genomen.

Kortom, een commerciële bank is in de loop der tijd verworden van een bedrijf dat probeert te verdienen aan het aantrekken en uitgeven van geld, tot een instelling die is aangesteld als (overheids)waakhond ter bestrijding van witwassen van geld, terrorismefinanciering en naleving van internationale VN-/EU-sancties. ${ }^{10}$ Als je kijkt naar de organisatie van een moderne commerciële bank zie je functies als compliance officer, risk manager, money laundering reporting officer et cetera die allemaal drukken op de bedrijfsomzetten maar in wezen geen onderdeel uitmaken van het bedrijfsmodel om geld te verdienen. Het is derhalve verrassend te zien dat ondanks al deze kostenposten, want de voornoemde personen zijn meestal duurbetaalde gespecialiseerde krachten, lokale banken toch nog winst weten te maken. De Aruba Bank noteert een nettowinst voor 2020, het coronajaar, van $f 22,5$ miljoen, hetgeen wel de helft is van het jaar daarvoor, ${ }^{11}$ maar toch. De Maduro \& Curiel's Bank verdiende in 2019 netto $f$ 147,5 miljoen en in $2018 f 194$ miljoen, een recordwinst. ${ }^{12}$ Hoe doen ze dat?

Een van de manieren om winst te blijven maken is, behalve extra bezuinigen op personeel (inkrimpen) en bedrijfskosten (afstoten filialen, verschuiving van fysiek naar online banking), goed te kijken naar de soort klanten. In de financiële wereld bepaalt risk appetite (risicobereidheid) in hoeverre een bank bereid is om diensten te verlenen aan een bepaald soort particuliere of zakelijke klanten. Hoeveel risico's wil je lopen met je klanten, zowel particuliere als zakelijke klanten? In beginsel geldt hier de privaatrechtelijke contractvrijheid voor de bank om zelf te kiezen wie zij als klanten aannemen en behouden. ${ }^{13}$

\section{Klanten van commerciële banken}

\subsection{Particuliere klanten}

Eerst de particuliere klanten. Controle van particuliere klanten is niet veel anders dan van zakelijke klanten voor wat betreft witwassen en financiering van terroristische activiteiten (Costumer Due Dilligence of CDD). Sommige particuliere klanten verdienen extra controle (Enhanced CDD) zoals bijvoorbeeld Politically Exposed Persons (PEP's). ${ }^{14}$ Vanuit een winstoogmerk wil de bank uiteraard alleen klanten hebben met een regelmatig en het liefst hoog inkomen omdat deze veel transacties verrichten waaraan te verdienen valt. Het is om deze reden dat banken bij aanvraag van een bankrekening onder meer de laatste drie loonstrookjes willen zien. Daarmee wordt meteen een grote groep mensen uitgesloten die om de een of andere reden niet aan deze eis kan voldoen. Dit zijn meestal mensen aan de

10 Overigens is het initiatief om toezicht te houden ontstaan in de boezem van de financiële wereld zelf om een betrouwbaar speelveld te behouden. In Nederland is daartoe destijds de particuliere Stichting toezicht effectenverkeer (Ste) opgericht die is opgevolgd door de Autoriteit Financiële Markten (AFM), een overheidsinstelling.

11 Antilliaans Dagblad 26 februari 2021.

12 Antilliaans Dagblad 28 april 2020.

13 I.S.J. Houben, 'Contractvrijheid voor de bank? Opzegging van een betaalrekening', Maandblad voor Vermogensrecht 2020, afl. 7/8, p. 287-293.

14 J. Sybesma, 'Jagen rechters PEP’s de illegaliteit in?', CJB 2016, afl. 2. 
onderkant van de inkomensladder dan wel AOV-gepensioneerden en/of buitenlanders. Echter, met een dergelijke houding wordt door banken een maatschappelijk probleem in stand gehouden, omdat overheid en bedrijven steeds meer online transacties vereisen in plaats van cash, ${ }^{15}$ hetgeen inhoudt dat men rekeningen via een online betalingssysteem moet voldoen, terwijl bepaalde burgers niet makkelijk aan een bankrekening kunnen komen. Behalve dat grote groepen burgers niet of nauwelijks toegang hebben tot internet, ${ }^{16}$ hebben zij ook geen bankrekening om elektronische transacties te kunnen doen. Ze krijgen gewoonweg geen bankrekening. ${ }^{17}$

In Nederland heeft sedert 2016 iedereen recht op een zogenoemde 'basisbetaalrekening'. Op grond van artikel 4:71f Wft moet een bank aan particulieren de mogelijkheid van een basisbetaalrekening bieden, waarbij de basisbetaalrekening bepaalde diensten moet omvatten. Dit moet kosteloos of tegen een redelijke vergoeding geschieden. ${ }^{18}$ Deze verplichting is gebaseerd op een richtlijn van de Europese Unie die al sedert 2014 bestaat. $^{19}$ Deze regelgeving kennen we niet in het Caribische deel van het Koninkrijk, waardoor alle inspanningen om digitaal te gaan spaak lopen omdat niet iedereen online transacties kan verrichten. Recentelijk heeft de CBCS kenbaar gemaakt ook zo'n wettelijke regeling voor te staan. ${ }^{20}$

\subsection{Zakelijke klanten}

Dan de zakelijke klant. Daarbij moet onderscheid gemaakt worden tussen bestaande klanten en nieuwe klanten. Zoals hiervoor geschetst, is de commerciële bank door de wetgever in de loop der tijd een steeds knellender korset omgebonden. Banken moeten steeds meer onderzoeken en controleren of zakelijke klanten wel door de beugel kunnen voor wat betreft witwassen en financiering van terroristische organisaties. Doen ze dat niet dan lopen ze risico dat ze lokaal door toezichthouders beboet worden dan wel op internationale zwarte lijsten komen te staan. Dit laatste heeft vooral te maken met de zogenoemde correspondentbanken, zusterbanken in het buitenland waarmee op en neer internationale transacties worden verricht. Het probleem van de correspondentbanken is op zich al een verhaal apart maar het gaat te ver om hier nader op in te gaan. ${ }^{21}$

15 A. Mollen \& J. Eleonora, 'Digitalisering van de overheid anno 2020', in: Raad van Advies Curaçao, Jaarverslag 2019, https://raadvanadvies.spin-cdn.com/67/47/764/file/20200616_jaarverslag_2019_rva.pdf.

16 Rapport CBCS en CBS, Household's Financial Affairs in Curaçao 2020, https://cdn.centralbank.cw/media/ research/20201109_households_financial_affairs_in_curacao_2020.pdf.

17 'Banken, klanten en integriteitsrisico's', Antilliaans Dagblad 18 februari 2021.

18 Implementatiewet toegang basisbetaalrekening, Stb. 2016, 386, in werking getreden per 11 november 2016 , Stb. 2016, 423.

19 Richtlijn 2014/92/EU van het Europees Parlement en de Raad van 23 juli 2014 betreffende de vergelijkbaarheid van de in verband met betaalrekeningen aangerekende vergoedingen, het overstappen naar een andere betaalrekening en de toegang tot betaalrekeningen met basisfuncties (PbEU 2014, L 257/214).

20 'CBCS considering legislation for banks to provide basic services', Curaçao Chronicle 10 maart 2021, https:// knipselkrant-curacao.com/cc-cbcs-considering-legislation-for-banks-to-provide-basic-services.

21 T. Alleyne e.a., Loss of Correspondent Banking Relationships in the Caribbean: Trends, Impact, and Policy Options (IMF Working Paper WP/17/209), IMF 2017, www.imf.org/en/Publications/WP/Issues/2017/09/29/Loss-ofCorrespondent-Banking-Relationships-in-the-Caribbean-Trends-Impact-and-Policy-Options-45220. 
Het is begrijpelijk dat banken bestaande zakelijke klanten die een steeds risicovoller, op grond van de algemeen opgelegde regels en de eigen risk appetite, profiel vertonen, willen afstoten. Basisregels van contractrecht en kleine lettertjes bij de rekeningovereenkomsten geven de bank in beginsel deze vrijheid. Banken zijn bevoegd tot opzegging van de bancaire relatie, mits de opzegging redelijk en billijk is. Die redelijkheid en billijkheid wordt mede ingekleed door de bancaire zorgplicht: ${ }^{22}$ de bank moet bij de opzegging acht slaan op de belangen van de klant. ${ }^{23}$ Dus, gezien de speciale relatie die commerciële banken hebben met hun klanten, dienen dit soort beslissingen met extra zorg te worden genomen. De zogenoemde zorgplicht maakt dat het niet zo makkelijk is voor een commerciële bank om een zakelijke klant af te stoten. Hetzelfde geldt zelfs voor het aannemen van nieuwe klanten. Die kunnen ook niet zomaar zonder goede redenen worden geweigerd. Hierna wordt ingegaan op enkele recente lokale uitspraken waarin de rechter toetst of die zorgplicht al dan niet is nagekomen; er zijn echter meer uitspraken te vinden, zeker als ook Nederland meegenomen wordt.

\section{Jurisprudentie}

Een activiteit die al gauw als risicovol wordt beschouwd is gokken. Dat kan via casino's maar ook via loterijen. Beide zijn niet verboden doch wel gereguleerd door de wetgevers. Feit is dat hier veel geld in omgaat waarbij witwassen al gauw in beeld komt. Mag de commerciële bank weigeren om een rekening voor een dergelijk bedrijf te openen dan wel de bestaande relatie verbreken?

De rechter bepaalde dat banken hun relatie met strafrechtelijk veroordeelde rekeninghouders in de loterijbranche mogen opzeggen. ${ }^{24}$ Voor wat betreft het opzeggen van een casinorelatie wordt dat door de rechter in Sint Maarten verboden ${ }^{25}$ en stelt het Hof voor een casino in Aruba $^{26}$ dat opzegging te vroeg is. De bank moet het casino de kans geven zijn interne procedures op orde te brengen opdat niet gevreesd hoeft te worden voor herhaling van overtredingen of andere ongeregeldheden die de relatie van de bank met haar correspondentbanken in gevaar zou kunnen brengen of de reputatie van de bank zou kunnen schaden. De einduitspraak moet nog komen. Echter, in een vergelijkbare zaak in Sint Maarten, ${ }^{27}$ die ook handelt over het opzeggen van een casinorelatie, oordeelde het Hof dat het de uitspraak van het GEA volgt en neemt het grote delen van de overwegingen integraal in zijn vonnis over. Het geeft een mooi beeld van hoe de rechter hierover denkt.

Het Gerecht stelt onder meer dat het geschil zich afspeelt in de context van verandering en verscherping van internationale en nationale regels op het gebied van het opsporen en tegengaan van criminele activiteiten, zoals het witwassen van drugsgelden en fraudeop-

22 Art. 2 lid 1 Nederlandse Algemene Bankvoorwaarden (ABV).

23 L. Hermans, 'De bancaire zorgplicht in het licht van de Wet ter voorkoming van witwassen en financieren van terrorisme', NSO Eques 28 januari 20121, https://equesnijmegen.nl/de-bancaire-zorgplicht-in-het-lichtvan-de-wet-ter-voorkoming-van-witwassen-en-financieren-van-terrorisme.

24 GEA Curaçao 19 maart 2019, ECLI:NL:OGEAC:2019:63.

25 GEA Sint Maarten 3 februari 2017, ECLI:NL:OGEAM:2017:3.

26 GHvJ 28 juli 2020, ECLI:NL:OGHACMB:2020:183.

27 GHvJ 15 mei 2020, ECLI:NL:OGHACMB:2020:134. 
brengsten en het financieren van terroristische activiteiten. In casino's gaat veel contant geld om en dat maakt hen aantrekkelijk en kwetsbaar voor deze activiteiten. Landen in het Caribisch gebied hebben niet altijd het wettelijke en organisatorische toezicht op orde om controle te houden en zo nodig in te grijpen. Casino's in het Caribisch gebied worden daarom in rapporten over dit onderwerp vaak als 'high risk' aangemerkt. Ook banken die in het buitenland als correspondentbank een onmisbare schakel vormen in het internationale geldverkeer willen niet met criminele activiteiten in verband worden gebracht en onthouden hun dienstverlening aan banken die daarin betrokken zijn of kunnen worden. Aan de andere kant is de casinobranche voor de economie en werkgelegenheid van Sint Maarten van groot belang en kunnen casino's niet zonder bankrekeningen. Wanneer casino's niet meer over lokale bankrekeningen kunnen beschikken zal dit hoogstwaarschijnlijk tot sluiting leiden dan wel tot een toename van het gebruik van contant geld met alle negatieve gevolgen en risico's van dien. De bank heeft weliswaar het recht om een einde te maken aan de bankrelatie met eisers omdat deze volgens haar een te groot risico vormen, maar zij dient daarbij zorgvuldig ten opzichte van eisers te handelen en de gerechtvaardigde belangen van eisers, alsmede de maatstaven van redelijkheid en billijkheid in acht te nemen, aldus het Gerecht. Mede vanwege de omstandigheid dat casino's voor hun voortbestaan afhankelijk zijn van hun bank houdt de zorgplicht van de bank in dat zij dient mee te werken aan het vinden van een oplossing. De bank heeft dat laatste in dit geval in onvoldoende mate gedaan. Een belangenafweging valt derhalve ten nadele van de bank uit en de conclusie is dat de opzegging van de bankrelatie met eisers thans in strijd is met de jegens hen in acht te nemen zorgvuldigheid en met de maatstaven van redelijkheid en billijkheid.

Recentelijk oordeelde de rechter op dezelfde wijze inzake het opzeggen van de bankrelatie door de RBC bank in Aruba ${ }^{28}$ én in $\mathrm{Curaçao}^{29}$ met Union Caribe, een geldtransactiekantoor. "Bij deze stand van zaken verzetten de redelijkheid en billijkheid zich tegen de opzegging door RBC”, aldus de KG rechter.

Ook nieuwe zakelijke klanten mogen banken niet zomaar weigeren. ${ }^{30}$ De rechter (in kort geding) heeft in de in de inleiding aangehaalde zaak waar het gaat om het aanvragen van een bankrekening gesteld dat de vrees van de bank voor reputatieschade als gevolg van de omstandigheid dat $\mathrm{O}$ als verdachte is aangemerkt in een nog lopend strafrechtelijk onderzoek ter zake van vermoedelijk gepleegde fraude en corruptie pas beducht hoeft te zijn als $\mathrm{O}$ onherroepelijk is veroordeeld. In een rechtsstaat geldt immers nog steeds en onverkort de presumptie van onschuld. De omstandigheid dat $\mathrm{O}$ een (gewezen) politiek prominente figuur (een zogenoemde PEP) is makt dit niet anders. Een redenering waar

\section{GEA Aruba 17 februari 2021, ECLI:NL:OGEAA:2021:86.}

GEA Curaçao 1 april 2021, ECLI:NL:OGEAC:2021:56.

Het is nog ingewikkelder indien een eerdere zakelijke relatie is verbroken vanwege een strafrechtelijk onderzoek en de ex-relatie wil, na sepot door het OM, vervolgens weer een nieuwe rekening openen, hetgeen de bank weigert. Deze Nederlandse kwestie ligt nu bij de Hoge Raad. PG Hartlief heeft sympathie voor het standpunt dat de contractsvrijheid van de bank zou moeten wijken voor het grote belang dat bedrijven hebben bij het kunnen gebruik maken van een betaalrekening. Maar het gaat te ver om, zonder een wettelijke regeling, eenzelfde bginselplicht tot het aanbieden van een (zakelijke) betaalrekening aan te nemen als voor consumenten aan de orde is. Parket bij de Hoge Raad 12 maart 2021, ECLI:NL:PHR: 2021:239. 
juridisch best wat op af te dingen valt; immers, de onschuldpresumptie geldt voor de relatie met de overheid en al haar organen (o.a. ministers, rechters), niet voor burgers. ${ }^{31} \mathrm{De}$ bank is in hoger beroep gegaan tegen deze uitspraak en heeft tevens in dit kader een vordering (ex art. $272 \mathrm{Rv}$ ) ingesteld bij het Hof tot schorsing van de tenuitvoerlegging van hetgeen de kortgedingrechter heeft bevolen, namelijk om binnen 24 uur een rekening te openen. Deze vordering is echter afgewezen. ${ }^{32}$

\section{Conclusie}

Concluderend kom ik tot het volgende. Banken zijn niet zomaar zakelijke instellingen die conform de regels van Boek 2 BW en corporate governance-regels opereren. Zij hebben te maken met stringente en uitgebreide toezichtregels vastgelegd in toezichtwetgeving en gehandhaafd door centrale banken. Daarnaast dienen zij zich in hun zakelijk verkeer met natuurlijke en rechtspersonen te houden aan een uitgebreide zorgplicht jegens hun klanten en potentiële klanten. Deze zorgplicht is nader uitgewerkt in diverse uitspraken van de rechter. Eigen belang dient terdege te worden afgewogen tegen dat van de klanten. Dat daarbij vaak het belang van de klanten voorgaat op dat van de bank zelf is inherent aan het karakter van een commerciële bank. Het dient ter facilitering van klanten bij het persoonlijke en zakelijke financiële verkeer. Aangezien alternatieven steeds minder worden steeds minder cashtransacties, digitaal betalingsverkeer niet alleen nationaal maar ook internationaal - wordt de zorgplicht van banken steeds groter. Het antwoord waar die zorgplicht eindigt is vooralsnog niet volledig duidelijk en deze (rechts)vraag zal de komende tijd nog veel rechtszaken opleveren.

Er is hier geen plaats voor een verdere uitwijding over de diverse aspecten die aan de orde zijn gekomen: voorkomen van witwassen en/of financiering van terrorisme, Know Your Customer, (E)CDD, zorgplicht, de-risking, risk appetite, correspondentbanken et cetera. Er is op dit gebied veel literatuur te vinden. Voor onze regio verwijs ik graag naar recente artikelen van M. van der Beek \& R.F. van den Heuvel, 'Tussen poortwachtersfunctie en toegang tot een nutsvoorziening: over de zakelijke betaalrekening in het Koninkrijk', Tijdschrift Financieel Recht in de Praktijk 2020, afl. 6, p. 64-74 en K. Frielink, 'De-risking en banken in het Caribische deel van het Koninkrijk', Tijdschrift voor Sanctierecht \& Onderneming 2021, afl. 1/2, p. 5-12.

31 'Iedereen recht op een bankrekening?', Antilliaans Dagblad 10 maart 2021.

32 GEA Aruba 3 februari 2021, ECLI:NL:OGEAA:2021:33 en GHvJ 12 maart 2021, ECLI:NL:OGHACMB: 2021:67. 